\title{
La obertura del tiempo social
}

\author{
Jahir Navalles Gómez \\ Universidad Autónoma de Tlaxcala \\ inavalleg@terra.com.mx
}

\section{Resumen}

Cada experiencia compartida es un acto de tiempo social, el presente trabajo interviene por ello, y así, habrá de reconocerse que el tiempo tercia como el depósito social de acontecimientos significativos sumidos en una idea, un recuerdo o un afecto, tanto una emoción como un sentimiento igual de disperso y compartido, postulando entonces que la misma sociedad, bajo esta misma dinámica, es un recorrido en el tiempo social.

Es, ese recorrido, esa narrativa de múltiples episodios donde se localizan, refieren, aglutinan, prevalecen todos los acontecimientos, que entre la permanencia y la irruptibilidad, la estabilidad y la identidad, entre la perspectiva del presente y la prospectiva del pasado, bosquejan la continuidad que en su misma esencia volátil vuelve todo acontecimiento intangible, impalpable, tal y como si nada hubiera cambiado, materializando a su vez una contraparte, aquella que refiere a la transformación constante y gradual; la intención será la de señalar, reconocer y reclamar el papel del tiempo social como aquel sendero imperceptible bajo el cual es posible, entre otras cosas, identificar el eslabón que implica al pasado en el presente, volviéndose todo acontecimiento, toda experiencia, tan eterna o inaprensible, tan efímera como sea posible, algunas veces inaccesible otras irreconciliable, donde se insinúa que es la propia sociedad la que se reconocerá en el trayecto.

Palabras clave: Tiempo social, acontecimiento, continuidad

\section{0.- Tiempo social: perspectivas y prospectiva}

Cada sociedad se concibe en el tiempo social, esto es así porque en su propio transcurrir toda sociedad se reconoce, recupera extractos, episodios, sentires, juicios así como esperanzas; y sucede, a la par, que de la esencia de la cual se desprende cada evento ocurrido se va esbozando una estela en la que se plasman, más allá de los grandes héroes vueltos personajes inmortales, de los eventos que ocurrieron en un día, hora o mes específico, de las caídas o desastres económicos que marcaron una época (el año 1994 en la sociedad mexicana sería un buen ejemplo) series, eslabones, encantos y desencantos que vuelven sólido lo etéreo del tiempo que ha pasado, que ha concurrido, donde han confluido tanto ideas como sentimientos colectivos y que remontasen tanto lo eterno y duradero como esa psicología de los pueblos de la cual hablase Wundt (1912) o lo que deviene de alguna civilización según Norbert Elias (1977), presentando a su vez a su contraparte, como lo que lo son esos contenidos tan efímeros, supuestos e inaprensibles que se rearman bajo un sentimiento tal como lo refería en algún instante Octavio Paz (1993). 
Con respecto al tiempo social, a decir de Ramón Ramos (1992), éste es sólo una metáfora expresiva y mucho muy cómoda, la cual no promulga un tiempo exclusivo sino una secuencia donde se resaltan los aspectos temporales de la realidad social, en forma más afable, es el transcurrir de la sociedad en sus propios rasgos temporales (p. $\mathrm{XI}$ ). $\mathrm{Y}$ para fines psicosociales, el tiempo social bien se concibe como la vía, el tren y el mismo pasajero que van sobre el camino, observando, aspirando, reflexionando y murmurando, algunas veces gritando, sobre qué es lo que sucede en el trayecto, reflejándose, omitiéndose, reconociendo algunas veces los inicios intentando, casi siempre, advertir un final.

Es así que en tan solo un instante, alrededor de lo que ha pasado, el pasado se vislumbra en el pasaje del tiempo social, en aquella imagen que según William James (1890) insinuaría la evocación y en ella, cada parte, elemento, personaje o sujeto, prenda o aroma, como ese sabor de la infancia sobre el que escribe Proust, aquella última palabra que se dicen los enamorados al despedirse, ese vislumbre ritual que queda al salir de casa, encamina el recuerdo, el rearmar el mismo, el sufrirlo nuevamente, porque ese acontecimiento marca el camino a seguir y el tiempo mismo que se requiere o se dispone para continuar, sea con el proyecto, la idea, la oración que queda incompleta porque no hay más presencias que se encuentren en ese sendero recorrido, y el empeño por buscarlas es lo que hace que todo sea pausado o acelerado, abrupto o cándido, fugaz hasta no poder tocarlo o con toda la lentitud para llegar a contemplarlo, tanto es así que habría de preguntarle por ese instante a Momo, aquella niñita-personaje descrito por Michael Ende (1973).

Y más allá de la ficción, lo que veladamente describe Ende a partir de su Momo, es el encontrar lo que el tiempo pudiese encerrar en algún momento y el grado en el cómo la velocidad de la cual estaría impregnado es lo que delimitaría una sociedad. El tiempo visto desde Momo, esa extraña no especialista, es uno que mientras transcurre no es prácticamente el mismo, es un tiempo dado en diversas dimensiones, resaltándose esa que lo rebosaría, donde de lo que se trata es de rellenarlo ("re" porque ya estaba lleno) de eventos que no causan ningún sentido, reacción, mezcla o revoltijo afectivo, y que sería la forma ideal para dar cuenta de él, ya que con base en la saturación se pretende colmarlo, se trata entonces de no dejar tiempo que se preserve si no siempre uno que estaría en función de algo, esto para que ni siquiera un respiro se permita para poder voltear la mirada.

Así las cosas, el tiempo al intentar concebirse como una entidad psicosocial, lo cual es la sugerencia de este texto, intenta volver la vista para encontrar en ese fragmento de sí algún significado que pueda sugerir una clave para darle sentido al presente, el pasado entonces puede ser remontado, reargumentado, aludido. Bajo la disposición tanto por contemplar, por engarzar, por rastrear, por nuevamente mirar lo que ya se había visto, uno bosquejaría el recuerdo, proyectando el terreno que ha cimentado al tiempo social para el actuar, evitando que lo que se vio, escucho, palpo y que fue doloroso, indignante, inimaginable, encantador, impresionantemente hermoso, vuelva o no a ocurrir, porque de eso está recreado el tiempo, de esos sucesos y miradas alrededor y de las que nadie sabe nada, que sin embargo se reconocen porque estarían exigiendo una respuesta o una pregunta, en el por qué y el cuándo aparecieron ${ }^{1}$. Esos eventos aún cuando nadie comente de ellos son parte del sendero que recorre el tiempo social.

1 Las cruces en el desierto de Cd. Juárez, Chihuahua, la permanencia por tanto tiempo de campos de concentración -tanto los virtuales, los no aceptados (Vidal-Naquet, 1987) y los clandestinos (Calveiro, 2001)- del por qué nadie habló (hasta ahora) de las matanzas impunes, de las injusticias locales, de los 
Porque los significados y el sentido descrito pueden localizarse igualmente en la reconstrucción de la mirada conjunta ${ }^{2}$, esa que queda plasmada en ese lado fascinante que musita la vida diaria, como lo que perdura de la caricia perfecta o de la frase exacta, el abrazo hecho tiempo invaluable y que muchas veces serán más inapreciables, por imperceptibles, hasta ese momento en el cual el encanto que surgió de ellos surtió su efecto, vale así recapitularlo colectivamente, intentando volver a compartir, a convivir bajo ese acontecimiento hilvanado de tiempo, y este argumento ya lo había conspirado a su vez Octavio Paz (1993, p. 28) cuando dijo: "El tiempo de un suspiro: una eternidad".

Sobre ello se pueden concebir conclusiones distintas a las propuestas por el historiador francés Fernand Braudel $^{3}$ en su argumentación sobre la larga duración (1958), percibiendo acompasadamente esa otra cara de la moneda en la que se asienta la sociedad, esto es, resignificando el mismo escenario del tiempo social, al cual el historiador así lo definía: "El tiempo social es, sencillamente, una dimensión particular de una determinada realidad que yo contemplo" ( $p$. 99), habría que agregarle que además se comparte, o se puede diluir en la desesperanza, en la desilusión, en el coraje del por qué sucedió y sigue sucediendo o en los oídos sordos de los que no

abusos de autoridad en su país. Cada cual un relato que intenta permear en la conciencia, y que recurre al tiempo en un afán de ser interpretado, vislumbrado, interpretado. Es así que todo relato desprendido en el tiempo toma forma y aduce contenidos en el testimonio, que como narración gradual confronta y recupera los eventos acaecidos. La relevancia del testimonio es crucial para la recreación de un recuerdo, y es tanto como decir que alguien más "estuvo ahí", que ese evento enmarcó las vidas y que sucedió, también, en esta "otra" forma que lo está relatando. A ciencia cierta, y sin intentar ser exhaustivos, un testimonio lo que hace es describir lo qué fue, localiza y reconoce el lugar de paso de la memoria colectiva, es una manifestación cabalmente apegada a un cierto evento. Y como dijera Halbwachs, por ello es que existen múltiples memorias (Aguilar, 1992), así en plural, que son la alusión incompleta a la vivencia, y su relevancia es que se permiten desgarrar el discurso histórico "oficial" introduciendo discordancias y "nuevos" argumentos, volviéndose la novedad incomodidad para ese presente que ya estaba establecido.

2 La dimensión de "lo humano" aparece en las pausas y en la reaparición de la misma sociedad vía los testimonios, esto a partir de la figura del "testigo", porque se transforma y se presenta como la huella de lo sucedido, el sobreviviente que necesita contar, también, su versión. Señala Jelin que: "los sobrevivientes pueden hablar desde lo que observaron. [...] los sobrevivientes pueden dar testimonio como observadores de lo acontecido a otros y, al mismo tiempo, ser testigos de sus propios vivencias y de los acontecimientos en los que participaron"(2001, p. 80) y como muestra de ello están tanto Jorge Semprún o Primo Levi, así Rigoberta Menchú desde la sociedad guatemalteca o el maestro José Revueltas en el 68 mexicano. El testimonio como un ejercicio de la memoria, requiere tiempo, el paso del tiempo es lo que permite tener interlocutores interesados, inmersos, críticos e insuficientes para dar cuenta de los eventos que históricamente marcaron a toda sociedad, y que sirven para reconocer la propia capacidad, la relevancia, del testimonio, del recuerdo.

3 Sin el mínimo afán de personalizar una teoría, es obligado citar ciertos antecedentes, Braudel, discípulo y continuador de la tradición en la aproximación histórica realizada por Lucien Febvre y Marc Bloch, propone e introduce ciertos elementos que bien pueden ser argumentados psicosocialmente, enriqueciendo así la discusión. Con una influencia explícita de varios estudiosos, entre ellos Marcel Mauss y Frederic Ratzel, ese mismo que influyo a Wundt (1912), con coincidencias tácitas con el historiador belga Henri Pirenne y con una aversión pública hacia Max Weber, Braudel rearma al historia a partir del tiempo social, ejemplo de ello es lo que compendia Peter Burke (1990, p. 42), donde el historiador francés refería: “[...]una historia cuyo transcurso es casi imperceptible..., una historia en la que todo cambio es lento, una historia de constante repetición, de ciclos permanentemente recurrentes". Y acota la discusión de esta manera: "El verdadero objeto de estudio es esta historia 'del hombre en su relación con el ambiente', una especie de geografía histórica o, como Braudel prefiere llamarla, una 'geohistoria"' (p. 42). Máximo defensor de sus propios planteamientos y tenaz en sus argumentos Braudel aclara, y permítasenos citarlo in extenso: "Creo en una realidad de una historia particularmente lenta de las civilizaciones en sus profundidades abismales, en sus rasgos estructurales y geográficos [...] más lenta aún que la historia de las civilizaciones, casi inmóvil, existe una historia de los hombres en sus relaciones estrechas con la tierra que los sustenta y nutre: es un diálogo que no deja de repetirse, que se repite para durar, que puede cambiar y cambia en la superficie, pero prosigue, tenaz, como si tuviera fuera del alcance y la mordedura del tiempo (1950 citado en Revel, 1996, p. 72) 
quisieron y quieren escuchar esa realidad ${ }^{4}$. Una realidad que requiere tiempo, eso apela a la permanencia de toda sociedad.

Pasajes y episodios son entonces lo que se encuentran en el tiempo social, imágenes y representaciones de la vida compartida, de lo narrado, de lo descrito, de lo impuesto, bajo lo que alguien cuenta, remonta, así tiene cabida un grupo, colectivo o comunidad que se reconoce y que destila una identidad que se sustenta en recuperar su pasado, ese es el postulado central de la memoria colectiva (Halbwachs, 1925; 1950), donde el propósito y la intención más bien es su reinterpretación con matices del presente, y con todo ello es como se vislumbraría y a la vez se desvanecería esa identidad (Garzón, 1998, p. 22).

Es ese el eslabón entre el tiempo social y la memoria colectiva, porque en la búsqueda, redención, disolución, aniquilamiento, los instantes estriban en los propios eventos, cada cual siendo todo un acontecimiento, ya que en ellos, desde ellos, por ellos, se circunscriben tanto los significados compartidos como el sentido expreso, ahí está el instante mismo jugando con la realidad para mantenerla hasta lo último, ese instante, bien a bien, como tercia Abbagnano (1961, p. 686), será una especie de encuentro entre el tiempo y la eternidad. Y esa esencia propia del tiempo social bien la complementa William James cuando menciona: "[...] una cosa vista sólo una vez en la vida puede dejar en la memoria un recuerdo indeleble" (1890, p. 229), una premisa se deriva de todo ello, esto es sucintamente, que todo lo que es simple, todo lo que es incluso durable, será el don del instante (Bachelard, 1932), donde lo sencillo y lo complejo de toda situación quedan y embisten cada recuerdo, efímeros como una sonrisa, el coraje y las desilusiones entre enamorados, perpetuos como el amor maternal, la noción céntrica de las ciudades o el dolor social. Bien cabría aventurar que tanto el tiempo social y la memoria colectiva son la forma etérea de los acontecimientos sociales.

De regreso al discurso sobre la duración temporal, Braudel señala y critica el uso indiscriminado de los acontecimientos, así les llama él a los sucesos del día con día, en la historia (de ahí su aversión) ${ }^{5}$

4 La indignación proviene de la banalización de todo acontecimiento, sea impuesto sea sugerido, un desgaste, un agotamiento que lo vuelve lejano, distante, ajeno, y que proviene de su cuantificación gradual, la asimilación, la aceptación y el conformismo que envuelve a las ausencias, el asentir en el plural de la muerte (muertes= muchas, varias, incontables) serán un buen ejemplo, de ahí es que surge la responsabilidad y la importancia del testimonio como acto comunicativo, Alain Finkielkraut (1996) extrae de una novela lo dicho: "Cuando desaparecía alguien del mundo de los vivos, otro no ocupaba inmediatamente su lugar para hacer olvidar al muero, había un vacío donde él faltaba, y los testigos próximos o lejanos de su desaparición se quedaban desconcertados cada vez que su mirada se topaba con ese vacío" (p. 92), las ausencias que marcan toda una presencia pero que cuando sólo llegan a registrarse, una tras otra, o en cantidades estratosféricas, macabras, criminales, es que entonces pierde toda presencia cada ausencia, por ello es más cruel la realidad que la ficción, la narración, el testimonio de Pilar Calveiro permite vislumbrarlo: "Diez, veinte, treinta mil torturados, muertos, desaparecidos... en estos rangos las cifras dejan de tener una significación humana. En medio de los grandes volúmenes los hombres se transforman en números constitutivos de una cantidad, es entonces cuando se pierde la noción de que se está hablando de individuos" (1998, p. 30), de ahí surge la noción del soldado desconocido (Finkielkraut, 1996, pp. 90-91), de las cifras y del anonimato de lo ocurrido, bajo el cual siempre, después de que las voces están dispuestas a hablar se clama porque todo desaparecido es un personaje, un protagonista, una persona, un nombre. Así, siempre existe "el otro lado de la moneda", donde resurgen las versiones que requieren oídos para ser escuchadas, sustentadas en la perseverancia, en el tiempo social: “ las larguísimas listas de desaparecidos, financiadas por los organismos de derechos humanos, que se publicaban en los periódicos argentinos a partir de 1980 , eran un recordatorio de que cada línea impresa, con un nombre y un apellido representaba a un hombre (o mujer) de carne y hueso que había sido asesinado. Por eso eran tan impactantes para la sociedad. Por eso eran tan irritativas para el poder militar" (Calveiro, 1998, p. 30 paréntesis agregados).

5 Parece que las coincidencias también se dan entre la forma de concebir al tiempo y su permanencia, entre lo retraído y permanente, lo efímero y banal de un acontecimiento, la metáfora, la ironía y la narrativa que confirma lo anterior, o ya someramente lo pone a discusión queda entre las semejanzas que 
y plantea a la larga duración como la base en la cual se edifica el presente, donde existe un hilo conductor que supone y soporta el devenir, porque esa actualidad, esta actualidad proviene de muchos pasados, así decía: "Cada 'actualidad' reúne movimientos de origen y ritmo diferente: el tiempo de hoy data a la vez de ayer, de anteayer, de antaño" (р. 76). Entonces los cimientos de cualquier sociedad se juntan, cargan, levantan en el tiempo social, las costumbres y los mitos según Wundt (1912) y el mismo Braudel (1958) serían los ejemplos recurrentes. Aunque es Norbert Elias (1977) quien complementaría el cuadro, cuando señala que todo elemento es igualmente relevante para poder dar cuenta de lo que ha sucedido, la remisión mutua entre los objetos y las personas, las personas y sus relaciones, sus relaciones y su pensamiento, su pensamiento y su forma de conllevarlo, por ello es que habla de "composiciones" (pp. 44-45), esas mismas bien pueden dar cuenta de la "larga duración" (Braudel, pp. 60 y ss.) porque lo que le incumbe a ésta es, como acotaría el psicólogo alemán Wundt: "[...] allí donde la costumbre por su duración se hizo permanente" (1912, p. 40).

Para Elias (1977) esas "composiciones" minúsculas, pequeñas, medianas, cambian a una velocidad gradualmente imperceptible y aún con su transformación acompasada permanecen porque se han vuelto lo que comúnmente se reconoce como una costumbre, una forma expresiva que data y tiene arraigo, una esencia que se ha afianzado, por ende la velocidad de transformación es proporcional al tamaño de la composición, por ello las civilizaciones, los emplazamientos o cada sociedad se transforman tan lenta y paulatinamente, la democracia en México, la Catedral de Chartres y los matrimonios que llegan a sus bodas de platino serían el ejemplo exacto; esto es así porque no son únicamente los recursos materiales los que mutan sino también el pensamiento, los afectos y lo que hace que la sociedad se reconozca a sí misma, la memoria compartida.

En este caso los objetos, pertenencias, cosas que persuaden el juicio, todo lo que devenga materialmente una evocación serán menos pesados de cargar que cualquier pensamiento en sí o que cualquier recuerdo, será más fácil omitir la fecha de la agenda que borrarla de la conciencia, algo parecido postulaba William James: "[...] muchas cosas las pensamos como pasadas, no porque tengan una cualidad intrínseca, sino más bien porque están asociadas con otras cosas que para nosotros significan pasado" (1890, p. 484). Esa es la esencia del tiempo social, el acarrear, el sustraer, el provocar que algo quede incompleto porque es paulatino y la forma de nuevamente remontarlo proviene de lo extenso o de lo lacónico, de ser a la vez intenso para compensarlo, esa es la sugerencia y eso es lo sorpresivo del tiempo social, de la mirada en él y a través de él, así lo describiría Cortázar en alguno de sus personajes, [y es que decía el mismo]: “¿cómo pude haberte narrado mi vida en tan sólo dos minutos?".

Donde la reconstrucción del tiempo social provoca la reinvención en el mismo para actuar en consecuencia y para que de acuerdo al juicio de la sociedad, como sea que ésta se conciba, este o aquel acontecimiento se vuelva, o no, a repetir.

proponen el mismo Braudel y el filósofo James, habrá que citarlos por ello: “ [...]recuerdo una noche que pasé cerca de la bahía, envuelto en los fuegos artificiales de fosforescentes luciérnagas; sus pálidas luces resplandecían, se apagaban, volvían a brillar sin procurar a la noche una verdadera iluminación. Lo mismo ocurre con los sucesos; más allá de su brillo, prevalece la oscuridad" (citado en Burke, 1990, p. 40); y el norteamericano arguye así también: "Nuestra conciencia sería como el destello de una luciérnaga, que ilumina el punto que cubre en ese instante, pero dejando todo lo demás en completa obscuridad" (1890, p. 484). Véase en ello que cada uno habla de dos elementos que proveen y dan contenido al tiempo, y la luciérnaga sirve, a su vez, en el mismo ejemplo para hablar de, lo intensivo y lo extensivo de un acontecimiento. 
La propuesta histórica braudeliana sugiere tres niveles del tiempo social ${ }^{6}$, para ello dispone de un tiempo corto, otro con una mediana duración y finalmente la base en la cual se descubren los otros dos: la larga duración. Cada cual da cuenta de diversos eventos, de los acontecimientos, las coyunturas y las estructuras, siendo esta última donde está anclada la larga duración y su reflexión desde los estudios históricos bien ampliaría el panorama que sobre las concepciones de lo social o colectivo se habían desarrollado, pero no será suficiente.

Y es que no necesariamente la vida social está sustentada en ese tiempo hecho de sucesos, de cambios y postulados sociales, económicos, políticos, de los que siempre se esperará algo, a los que se les exigiría vaticinar su final, los cuales puede uno argumentarlos por sus orígenes visibles, proyectando así una sociedad dependiente de su tiempo y de sus ideologías. Excelente propuesta para referir lo económico, lo político más algo incompleta cuando se intenta dibujar la esencia de la sociedad. Así habrá de reconocérsele lo novedoso, que es que cada tiempo plantea una velocidad cada vez más pausada alrededor de la sociedad, y los eventos históricos algunas veces darían la impresión de ser intemporales porque el movimiento que deviene no es, la mayoría de las veces, percibido.

Y sobre ese tipo de eventos es que se ancla la vida colectiva, la que se vive diariamente, y que se difunde entre las voces, los sonidos, las imágenes, las expensas, las disculpas, los suplicios de la gente, eventos que tienen su propia esencia, algo que puede perdurar o diluirse de las conciencias, de esas que lo han vivido, de aquellas que lo han sufrido, de estas que intentan dar cuenta de él.

Valdría aclarar que en la argumentación de Braudel, es cada evento histórico el que bosqueja una velocidad temporal que va de lo inmediato y efímero hasta lo permanente y contemplativo ${ }^{7}$, recreando así lo que el tiempo social expone, luego entonces la forma ideal para hablar de la velocidad del tiempo es a partir de los sucesos que se encierran en él mismo, aquellos que se pudieran estirar lo más posible porque uno quiere que duren para siempre o reducirlos porque ya no se quiere saber nada más de ellos o porque son incomprensibles en ese presente; y esto bien se destinaría a cada acto significativo, a todo evento compartido, esto es, una canción, un desengaño, un enfrentamiento, un amorío, una guerra, los conciertos o las épocas que se esperan que nunca terminen, por lo cual tanto el requinto de Carlos Santana en cualquiera de sus canciones, el conflicto zapatista, el besarse al despedirse y el siglo XVIII tanto como el XX son una forma de acontecimientos, porque son de diario, porque han durado siglos, porque conllevan, comparten y confirman significados, y tanto la rapidez como la lentitud de los acontecimientos no puede ser predeterminada por nada ni por nadie,

\footnotetext{
6 La originalidad en la propuesta braudeliana radica en que transfigura los elementos, los contenidos convencionales en la historia económica. Sin la mínima intención por prescindir de ellos va hilvanando la historia con las categorías “clásicas”, es decir, "las categorías de 'agricultura', 'comercio' e 'industria’ y se pone a considerar la 'vida cotidiana', a 'las personas y las cosas', 'todo cuanto la humanidad hace o usa': alimentos, vestidos, viviendas, herramientas, dinero, ciudades, etcétera” (Burke, 1991, p. 51). La pauta a seguir es una que se sustenta en dos conceptos centrales: la vida cotidiana y la civilización material. Las críticas por supuesto no se hicieron esperar, enfocadas en ese tiempo largo que refería y alentaba una "inmovilidad histórica”,y que como señala Jacques Revel (1996, p. 72) tenía toda la forma de: “[...]las pesadeces, las inercias, [...], las evoluciones imperceptibles, con la convicción de que en ese nivel se ubican las realidades verdaderamente importantes”. Este autor recapitula, resaltando la relevancia, el trabajo y la propuesta braudeliana: "Su primero, su mayor libro, El Mediterráneo y Felipe II (1949), es sabido, está organizado en tres grandes partes. La primera está dedicada al tiempo casi inmóvil del medio geográfico del mar interior y a las condiciones casi permanentes que ha propuesto a la actividad de los hombres; la segunda trata acerca del tiempo social, en particular el de las fluctuaciones económicas que acompasan y orientan esta actividad a la escala del siglo, pero también el de los Estados y las sociedades; la última reubica los acontecimientos y la acción consciente de los hombres y se propone comprenderla a partir de las tramas precedentemente valorizadas” (p. 72).

7 En esencia, toda la propuesta braudeliana puede ser reducida a una frase hecha por el propio autor intelectual, quien decía: "Mi gran problema, el único problema que tenía que resolver era mostrar que le tiempo se mueve a diferentes velocidades” (1977 citado en Burke, 1990, p. 44). Ajeno es entonces que siempre se haga referencia al trabajo de Braudel como un trabajo de mentalidades, porque según dicen "A Braudel no le interesaban las estructuras o aparatos mentales, lo que Febvre llamaba outillage mental" y si hay que ser honesto en estos avatares, existe un desprendimiento entre el maestro y el discípulo, ya que: “[...] Braudel nunca mostró interés por la historia de las mentalidades” (Burke, 1990. p. 51)
} 
si no que es el acontecimiento el que delimita lo que puede hacerse, o no, para mantenerlo o desaparecerlo.

La indistinción de los acontecimientos gira así en torno a que cada vivencia es digna y creíble, y como tal es un acto revelador, porque lo que se dispone son los significados que rondan cada extracto tiempo y que delinearían un acontecimiento con visos de tangibilidad, de reconstrucción, de aceptación colectiva; y en ese andar pausado, más que nada lento que bien propone la larga duración, son las expresiones desprendidas de los actos, aquellas que suponen y sujetan el pasado, de la sociedad, persona, grupo, objeto o expresión (Giedion, 1948), civilización (Braudel, 1959; Elias, 1977), costumbre o práctica-ritual (Wundt, 1912), merece entonces una advertencia al reintroducir el tiempo como el eje y el depósito, el ancla y el sendero de la vida social, y es que lo que se intenta por su intervención es que, como dice Giedion: "[...] resulte visible la continuidad de los acontecimientos. Una época que haya perdido su conciencia de las cosas que informan su vida, no sabrá dónde se encuentra ni, mucho menos, qué es lo que busca" (1948, p. 17).

Sucede que las respuestas a las preguntas del ¿cómo?, ¿cuándo?, ¿dónde? que se plantea una sociedad tienen cabida en el tiempo social, y en cada andar, reconociendo su velocidad para contemplarla, se presenta toda la presencia y las ausencias, todo lo intensivo de cada evento, de la distancia recorrida para poder hablar de él, del movimiento que según Bergson (1934) acarrea pensamientos y sentimientos, de la forma abrupta en la que se presentó, de que no se tuviese conciencia de ello, donde la relevancia depositada en la temporalidad de los sucesos sirve de marco para localizar los eventos que se espera no ocurran nuevamente pero también permite que el pensamiento social se presente, aún de diversas formas o en indescriptibles contenidos, como los afectos, ilusiones, emociones, sentimientos, avatares y desilusiones de lo ocurrido en algún instante, que en una mirada, un abrazo o un beso, se condensen intemporalmente y bien pueden marcar y guiar el presente, darle sentido, hacerlo comprensible, y que aunque sea por ese instante el recuerdo tenga la forma de toda la sociedad.

Esta idea remite a un acto fiel de la conciencia, para ello habrá que recurrir al fisiólogo, psicólogo y filósofo William James, lo cual implica reconocer en estos avatares al interlocutor adecuado, porque será el también renombrado profesor de Harvard quien lo volverá explícito, eslabonando así el tiempo social, su concepción, con los actos que sugieren entonces la presencia de la memoria, la cual en su esencia, desde su argumentación, deberá presuponer la reminiscencia, la evocación, el recuerdo y la retención del acontecimiento recordado (1890, p. 523). Siendo esta última acotación la que desglosaría cualquier ejercicio de memoria: "[...] la retención de una experiencia no es otra cosa que dar otro nombre a la posibilidad de volverla a pensar, o la tendencia a pensarla otra vez, con todo lo que la rodea" (p. 524). La retención implica el re-conocimiento de un acontecimiento, pero para que éste pueda ser interpretado como tal deberá haber durado un cierto periodo de tiempo, desde dos siglos (y unos años más)-como la injusticia y las vejaciones sufridas por las comunidades indígenas en México- hasta una centésima de segundo -como el coqueteo cómplice- luego entonces el eslabón entre tiempo y memoria se reconoce bajo un estado substantivo (1890, p. 515).

Es por medio de sus acontecimientos que una sociedad se concibe, y no necesariamente ésta hace referencia a un imperio o a una comunidad, pueden ser también dos personas o el grupo de correspondencia, los que defienden y exigen sus derechos o los que reclaman justicia y libertad. Es ahí donde se localiza la dimensión psicosocial, en los flujos y en lo que lleva la corriente, en lo intensivo y en lo duradero de los eventos, en los grupos sociales a los que refiere así también en los bastimentos de la memoria, que para Adela Garzón (1998, p. 24) serían las catástrofes, los 
acontecimientos políticos, las guerras, donde se cruzarían los recuerdos y sus distorsiones, la memoria y la historia y las múltiples formas afectivas que se revelasen de ellos.

Donde no se intenta "banalizar" lo sucedido, el abordarlo permite reinterpretarlo, la aproximación, psicosocialmente hablando, busca la tónica, el flujo constante de lo ocurrido, cómo se ha proyectado, cuestionando las diversas maneras en las cuales se llevo a cabo, las posibilidades de reconciliación así también los dimensiones disputadas, recubriendo toda sociedad bajo la entidad del tiempo social y vislumbrándola no como un evento finalizado sino como uno al cual le restan discursos, donde se multiplican personajes, desde el que se suman voces y relatos e irónicamente se dividen las versiones. Todo ello será acogido en cualquier fragmento, episodio, resonancia (Halbwachs, 1939), frasecilla melosa o mueca infantil, disputa marital, donde su duración repercute y sobrepasa, vuelve entonces reconocible, comprensible y permanente cualquier recuerdo, pensamiento (James, 1890), sentimiento (Paz, 1993).

Las fechas, que exclusivamente servirían para localizar sobran, no así las horas, los lustros, aquellos "5 minutos" que son relevantes porque será la mismísima alusión al acontecimiento demarcado, de ahí la necesidad de comunicarlo, de expresarlo, de compartirlo, porque si el tiempo se narra para hacerse comprensible es por la necesidad de permanencia, esto es, de reconocerse en el ritmo que despliegan cada uno de los acontecimientos envueltos en el tiempo y en lo breve o prolongado de los mismos.

El derrotero proviene de los actos en los que se involucra la percepción social, postulando que el acto del recuerdo no es simplemente recordar sino también percibir -el propio Halbwachs, mentor del término memoria colectiva (Aguilar, 1992), no solamente refería la memoria colectiva- escudriñando y rastreando eslabones, orquestando al pasado con la perspectiva del presente, reconciliando los tiempos y las ideas, las esperanzas y los infortunios, a cada individuo y a todo personaje invocado en el recuerdo, en el pensamiento, así, nuevamente, el único amigo de Bergson (Barlow, 1966), James, propondría: "pensar en una cosa como pasada es pensarla entre los objetos o en la dirección de los objetos que en el momento presente están afectados por esta cualidad. Tal es el original de nuestra noción del tiempo pasado, sobre el cual nuestra memoria y nuestra historia [se] construyen" (1890, p. 484).

\section{1.-Tiempos del pensamiento social}

¿Cuál es el sustento del tiempo social?, esa pregunta sobrevuela la conciencia, porque si éste sobreviene en cada acontecimiento descrito en él, lo que preocupa entonces a cada grupo, personaje, individuo, mandatario, activista político, es su duración, que sea corto o que cada vez se prolongue más, por eso siempre vienen las rechiflas en un partido de fútbol porque se desea que este llegue a su fin o que bien esos últimos minutos sean la esperanza del equipo, por eso Bob Dylan se tardó tanto tiempo en fascinar a su público, por eso se apresuró, aun sin quererlo, en desilusionarlos, esa misma razón tienen las comunidades zapatistas y los que claman por justicia, lógica muy diferente a los "15 minutos foxistas" en los cuales se pretendía conciliar el conflicto.

Por ello es que existe esa velada importancia de contener al tiempo en un instante, en que pueda permanecer, en que ya desaparezca, en que su inmanencia conlleve las soluciones adecuadas, 
aunque algunas veces no sean las que se esperan, en que éste no se diluya entre otras tantas cosas más, en esas forzadas "coincidencias" que saturan una fecha o un lugar, perdiendo todo su sentido originario, en esa dinámica se encuentran cientos de sucesos, los preludios o el suspenso a una respuesta, la demora que hace extenso el acontecimiento para dejarlo pasar, y el hartazgo que se genera de esperar algo que no valdría mucho la pena.

Por ello es que siempre habrá quien apele a la lentitud, porque la lentitud es el sentido de la continuidad, continuidad que se refleja en la contemplación, y que permite revisar lo que la memoria, y quienes estén implicados en el acto de recordar, aspirara, pretendieran retomar, porque ahí mismo se encuentra, se reencuentra la mirada de la sociedad que concurre, que lo observa, una necesidad imperiosa queda sujeta en la descripción del tiempo social, en la visibilidad desprendida que remonta los significados sociales de los acontecimientos vivenciados, relatados, compartidos.

Pareciera entonces que una sociedad se configura cual si fuese un reloj, desintegrando el tiempo social que es su esencia, sujetándolo en cada acontecimiento para hacerlo palpable, para dar cuenta de sí misma, para poder reconocerse en los otros, en los objetos, en las personas, en los rostros, en cada palabra, pero irremediablemente esta aprehensión tecnifica, desgasta, obliga, a que la sociedad se sature de acontecimientos efímeros, sólo para que el tiempo sea evaluado, para señalar y citar que algo "ha pasado", con el nulo interés por observar, por remontar, por pertenecer.

Proponer a la sociedad cual si fuera un reloj para nada es una imagen tétrica ${ }^{8}$, aunque sugiera una presencia técnica, mecanizada, irrelevante a menos que sea eficiente, como lo que sucede cuando alguien o todos voltean a ver la hora en su reloj, actividad, acto social o esfuerzo que sólo se realiza porque es necesario, porque habrá que llegar, porque habrá que terminar, porque habrá que comenzar. Pero la esencia de los relojes va más allá, sugiere comunidad, pertenencia, reconocimiento, refiere una vida colectiva (Cipolla, 1981), una que requiere visibilidad como la que dan esos relojes antiguos que persuaden toda la atención, que con el visto dado a su contemplación, el que contempla se hace uno con el mismo, con el tiempo, con la sociedad.

Ejemplos habrá que lo confirmen, donde cada reloj aprecia la visibilidad entre las partes, y describen un atónito estupor y una irrefrenable admiración por lo que se ha visto, las clepsidras por eso es que son toda una maravilla, la cual se acaba en cuanto se congela el agua, los relojes "de sol" a los cuales habrá que estar muy al pendiente porque si no la sombra te alcanza o en la mismísima atmósfera de tiempo espacializado de los relojes de arena, a la cual uno ve, y refiere, como si la sociedad fuera la que se estuviera diluyendo.

De ahí proviene la relevancia del tiempo, de sí este es largo como los regaños de los padres a los hijos o si es corto como el caso de los hijos a sus padres, de si es extenso y cansado como cualquier discurso político, de si es intenso como el abrazarse o besarse al reencontrarse, de si fue generoso porque no era necesario, de si es mezquino porque te exige algo.

\footnotetext{
8 La alusión a los relojes y su interlocución como expresiones de la sociedad, deviene no de una visión mecanicista o sustentada en el progreso, ni es consecuencia de la era industrial y de un pensamiento apegado a ella, bosqueja más bien la distorsión de los eventos, de la vida colectiva, de los significados originales, de la saturación social y de que como artefactos, producto y conciencia social, acarreen la despersonalización, la individualización y que bien reduce el panorama de la vida social y de los acontecimientos en los cuales ésta se gesta, cabe entonces anticipar que el tiempo simplemente, en la actualidad, bajo y en cada nuevo artefacto, se diluye
} 
La argumentación psicosocial es una que tiende o que intenta recupera lo significativo del tiempo social, por ello es que no le preocuparán los finales ni los principios, le interesa el saber cómo es que esto se está gestando, lo que sea, tiene una presencia, tiene una forma que se supone en el tiempo, de ahí provienen la interrogantes ${ }^{9}$, esa es la esencia psicosocial.

La propuesta es por lo lento de los acontecimientos y entonces el término no sería algo que refiere a un acto banalizado, intrascendente sino uno que por sus propios significados demande el ser recordado, recuperado, conmemorado.

La lentitud es frugal, porque como el tiempo se muestra extensa ya que recorrerá los mismos significados, en un instante, que a su vez articularía el presente y el cobijo de las miradas alrededor y que son una misma, sean entre dos o entre la audiencia, algo similar dice Bachelard sobre el presente, y esto para nada es coincidencia es pura relevancia, ya que señala que éste puede ser comprendido como el punto nodal del tiempo: "El presente no pasa, pues un instante sólo se deja para encontrar otro; la conciencia es conciencia del instante, y la conciencia del instante es la conciencia" (1932:46).

Así las cosas, si se concibe al tiempo social en lo significativo de cada acontecimiento vivenciado, también existirán los extremos, y los extremistas, como aquel citado por un cantante muy acostumbrado a hacer del tiempo un lugar común, cuyo nombre no tiene sentido convocar aquí, quien pregunta ¿quién me ha robado el mes de abril?, extraño por quien pueda vivir en un tiempo con acontecimientos sin significados, entre vivencias inaprensibles; en otro caso, uno bien puede hablar de las despedidas, porque como decía Kundera (1995), ahí se trata de hacerse más lentos, por eso es que las despedidas son acontecimientos tan extraños.

Ya para terminar, aún cuando el tiempo sea de lo más asfixiante, de lo más insoportable, de lo más desgastante, cuando por el reflejo de la misma situación vivenciada se sienta que te lleva la tristeza, que como decía José Alfredo, "la vida no vale nada", quedaría contrarrestarlo con algo, con la contraparte diría James, y eso sería el sonreír por sólo un segundo.

\section{Referencias}

Abbagnano, Nicola (1961). Diccionario de Filosofía. México: FCE.

Aguilar, Miguel Angel (1992). "Fragmentos de la Memoria Colectiva de Maurice Halbwachs" en: La Revista de Cultura Psicológica, Vol. 1, No 1. México. Facultad de Psicología, UNAM.

\footnotetext{
9 Valdría resaltar las proximidades cuando un cuestionamiento se hace desde diversas vertientes, su comprensión y más allá de eso su reinterpretación, remontar el presente con visos del pasado, el actuar pasado para que no se repita en el presente, esa bien pudo ser la intención del presente texto, plantear una crítica y volverse criticable como es que se supone todo conocimiento debe ser, por ello es que muchas veces se encuentran las analogías y se puede decir que la psicología social tendría que ser histórica, por los elementos a los que se refiere, por las vivencias que plasma, por los argumentos que no sobresalen, pero que pueden ser aludidos, así lo proponen tanto Braudel: "[...] todas las ciencias humanas son "encrucijadas" o, si se prefiere, puntos de vista diferentes sobre el mismo conjunto de realidades sociales y humanas. [...] Las fases de acercamiento permiten que las ciencias ya establecidas asimilen esos nuevos resultados. Así se desarrollaron la historia económica y social o la psicología social. (citado en Revel, 1996, pp. 86-87), como Tomás Ibáñez: "[...] esto lugares se vuelven sorprendentemente similares cuando se los interroga desde unas mismas preguntas"(2001, p. 9).
} 
Bachelard, Gaston (1932). La Intuición del Instante. México: FCE.

Barlow, Michel (1966). El Pensamiento de Bergson. México: FCE.

Bergson, Henri (1934). El Pensamiento y lo Moviente. París: Bibliothéque de Philosophie Contemporaine.

Braudel, Fernand (1958). "La Larga Duración" en La Historia y las Ciencias Sociales. México, Alianza Editorial. 1989. (pp. 60-106).

Braudel, Fernand (1959). "Aportación de la historia de las civilizaciones" en La Historia y las Ciencias Sociales. México: Alianza, 1989. (pp. 130-200).

Burke, Peter (1990). La Revolución Historiográfica Francesa. La Escuela de los Annales: 1929-1989. Barcelona: Gedisa.

Calveiro, Pilar (1998). Poder y Desaparición. Los Campos de Concentración en Argentina. Buenos Aires: Colihue.

Calveiro, Pilar (2001). Desapariciones. Memorias y Desmemorias de los Campos de Concentración Argentinos. México: Taurus.

Cipolla, Carlo M. (1981). Las Máquinas del Tiempo. Buenos Aires: FCE.

Ende, Michael (1973). Momo. México: Alfaguara-Promexa.

Elias, Norbert (1977). El Proceso de la Civilización. Investigaciones Sociogenéticas y Psicogenéticas. México: FCE.

Finkielkraut, Alain (1996). La Humanidad Perdida. Ensayo Sobre el Siglo XX. Barcelona: Anagrama.

Garzón, A. (1998); "Prólogo. Individualismo psicológico y memoria colectiva" en Páez, Darío; Valencia, José F; Pennebaker James W y Rimé, Bernard (eds.); Memorias Colectivas de Procesos Culturales y Políticos. Bilbao: Universidad del País Vasco. (pp. 17-27).

Giedion, Siegfried (1948). La Mecanización Toma el Mando. Barcelona: Gustavo Gili.

Halbwachs, Maurice (1925). Les Cadres Sociaux de la Mémoire. París: PUF.

Halbwachs, Maurice (1939). "La memoria colectiva de los músicos" en Ramos, Ramón: Tiempo y Sociedad. Madrid: CIS-Siglo XXI, 1992, (pp. 35-62).

Halbwachs, Maurice (1950). La Mémoire Collective. París: PUF.

Ibáñez, Tomás (2001). Municiones para Disidentes. Barcelona: Gedisa.

James, William (1890). Principios de Psicología. México: FCE.

Kundera, Milan (1995). La Lentitud. México: Tusquets.

Paz, Octavio (1993). La Llama Doble. Amor y Erotismo. México: Seix Barral.

Ramos, Ramón (1992). Tiempo y Sociedad. Madrid: CIS-Siglo XXI.

Revel, Jacques (1996). Las Construcciones Francesas del Pasado. Buenos Aires: Siglo XXI. 
Vidal-Naquet, Pierre (1987). Los Asesinos de la Memoria. México: Siglo XXI.

Wundt, Wilhelm (1912). Elementos de Psicología de los Pueblos. Bosquejo de una Historia de la Evolución de la Humanidad. Barcelona,:Alta Fulla.

\section{Formato de citación}

Navalles, J. (2004). La obertura del tiempo social. Athenea Digital, 6. Disponible en http://antalya.uab.es/athenea/num6/navalles.pdf

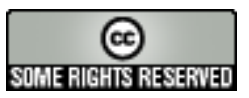

Este texto está protegido por una licencia Creative Commons.

Usted es libre de copiar, distribuir, exhibir y comunicar la obra bajo las siguientes condiciones:

Reconocimiento: Vd. debe reconocer y dar crédito al autor original.

NoComercial. Vd. no puede utilizar esta obra para fines comerciales.

NoDerivados. Vd. no puede alterar, transformar, o añadir nada a esta obra.

\section{Resumen de licencia}

Texto completo de la licencia 